\title{
Orchid Reintroduction Based on Seed Germination-Promoting Mycorrhizal Fungi Derived From Protocorms or Seedlings
}

\author{
Da-Ke Zhao ${ }^{1}$, Marc-André Selosse ${ }^{2,3}$, Limin Wu ${ }^{4}$, Yan Luo ${ }^{5}$, Shi-Cheng Shao ${ }^{5 *}$ and \\ Yong-Ling Ruan ${ }^{6 *}$ \\ ${ }^{1}$ Biocontrol Engineering Research Center of Plant Disease and Pest, Biocontrol Engineering Research Center of Crop \\ Disease and Pest, School of Ecology and Environmental Science, Yunnan University, Kunming, China, ${ }^{2}$ Département \\ Systématique et Evolution, UMR 7205 ISYEB, Muséum National d'Histoire Naturelle, Paris, France, ${ }^{3}$ Faculty of Biology, \\ University of Gdansk, Gdansk, Poland, ${ }^{4}$ Agriculture and Food, Commonwealth Scientific and Industrial Research \\ Organisation, Canberra, ACT, Australia, ${ }^{5}$ Gardening and Horticulture Department, Xishuangbanna Tropical Botanical Garden, \\ Chinese Academy of Sciences, Mengla, China, ${ }^{6}$ Australia-China Research Centre for Crop Improvement, School of \\ Environmental and Life Sciences, The University of Newcastle, Callaghan, NSW, Australia
}

OPEN ACCESS

Edited by:

Carlos Lucena

University of Cordoba, Spain

Reviewed by:

Songjun Zeng,

South China Botanical Garden, Chinese Academy of Sciences, China

Hironori Kaminaka,

Tottori University, Japan

*Correspondence:

Shi-Cheng Shao

shaoshicheng@xtbg.org.cn

Yong-Ling Ruan

yong-ling.ruan@newcastle.edu.au

Specialty section:

This article was submitted to

Plant Symbiotic Interactions,

a section of the journal

Frontiers in Plant Science

Received: 27 April 2021

Accepted: 04 June 2021

Published: 30 June 2021

Citation:

Zhao D-K, Selosse M-A, Wu L, Luo Y, Shao S-C and Ruan Y-L (2021) Orchid Reintroduction Based on Seed

Germination-Promoting Mycorrhizal

Fungi Derived From Protocorms or

Seedlings.

Front. Plant Sci. 12:701152. doi: 10.3389/fpls.2021.701152
Orchids are among the most endangered in the plant kingdom. Lack of endosperm in their seeds renders orchids to depend on nutrients provided by orchid mycorrhizal fungi (OMF) for seed germination and seedling formation in the wild. OMF that parasitize in germination seeds is an essential element for orchid seedling formation, which can also help orchid reintroduction. Considering the limitations of the previous orchid reintroduction technology based on seed germination-promoting OMF (sgOMF) sourced from orchid roots, an innovative approach is proposed here in which orchid seeds are directly co-sown with sgOMF carrying ecological specificity from protocorms/seedlings. Based on this principle, an integrative and practical procedure concerning related ecological factors is further raised for re-constructing long-term and self-sustained orchid populations. We believe that this new approach will benefit the reintroduction of endangered orchids in nature.

Keywords: symbiosis, seed germination, reintroduction, orchid mycorrhizal fungi, orchid conservation

\section{ORCHID REINTRODUCTION AND CONSERVATION: A GLOBAL URGENCY}

Orchidaceae is the second largest family of flowering plants after Asteraceae (Chase et al., 2015; Givnish et al., 2015; Willis, 2017), with a total of 29,199 species identified (Govaerts et al., 2017). They are tremendously valuable for biodiversity, conservation, and the production of a wide range of medicinal compounds, healthy food, and ornamental plants (Willis, 2017; Hinsley et al., 2018). Moreover, they are popular flagships for habitat conservation. However, orchids are currently among the most threatened flowering plants, with many species on the verge of extinction in the wild due to over-collection, loss of habitats, or climate change (Liu et al., 2015; Gale et al., 2018; Hinsley et al., 2018; Wang et al., 2019). Furthermore, most orchids require specialized habitats and are usually in small populations with a high dependence on pollinators, symbiotic germination fungi, and host trees for epiphytic species, further making them particularly vulnerable to extinction 
(Roberts and Dixon, 2008; Selosse, 2014; Fay et al., 2015; Rasmussen et al., 2015; Keppel et al., 2016; Fay, 2018; Gale et al., 2018).

Retrospectively, few orchid species have been domesticated and cultivated on a large scale, except for these with high values in ornamental horticulture (e.g., in the genera Cymbidium, Phalaenopsis, and Cattleya), medicine (several Dendrobium and Gastrodia spp.) or food industries (e.g., Vanilla fragrans). Consequently, a large portion of orchids still grows in their natural habitats. All orchids have been included in their entirety in Appendices I and II of the Convention on International Trade in Endangered Species of Wild Fauna and Flora (CITES) in 2017 to ban illegal trade (Gale et al., 2018; Hinsley et al., 2018). Based upon the assessments of 1770 orchid species worldwide in 2021 by Global International Union for Conservation of Nature (IUCN) for Red Lists of Threatened Species, nearly a half $(46.5 \%)$ of orchid species are under one of the three threat categories, namely, vulnerable, endangered, and critically endangered (IUCN, 2021). Clearly, the majority of orchids are facing extinction threats, which demands urgent attention and targeted conservation actions such as reintroduction (Roberts and Dixon, 2008; Rasmussen et al., 2015). Reintroduction means the controlled placement of plant individuals of an endangered species into its natural habitat or managed ecological area to re-establish populations in the wild.

\section{REINTRODUCTION AS A PRIORITY FOR EFFICIENT ORCHID CONSERVATION}

Ex situ and in situ conservation, together with reintroduction, are the main methods for the conservation of threatened plant species (Oldfield, 2009). For plants deprived of their original natural habitats, ex situ conservation in botanic gardens may be the only way for their survival in short to medium terms (Ren et al., 2014). Of the 350,699 categorized plant species, 105,634 or $30 \%$ are held in the living collections of the global botanic garden network, indicating a significant effort in ex situ conservation (Mounce et al., 2017). Botanic gardens are, however, are concentrated on temperate regions and a majority of the collected species is kept in the northern hemisphere (Mounce et al., 2017). It implies that a large number of orchids is beyond ex situ conservation, mostly growing in tropical and subtropical areas with high genetic diversity (Givnish et al., 2015).

In contrast to ex situ conservation, in situ conservation is considered to be more effective for sustainable biodiversity conservation. The procedure is, however, complex and multifaceted. It involves both the maintenance and management of the protected areas and actions required at the species and population levels. So far, species-level measures have only been undertaken for a very small percentage of threatened plants by a few countries, and with limited success (Heywood, 2015). Indeed, it is difficult to carry out efficient in situ conservation

\footnotetext{
Abbreviations: OMF, Orchid mycorrhizal fungi; sgOMF, Seed germinationpromoting orchid mycorrhizal fungi; rOMF, Root-originated OMF; sOMF, Seedoriginated OMF; SSR, Simple sequence repeats.
}

for most of the endangered orchids due to the vast number of species involved and their broad geographic distributions.

Reintroduction of individual plants to their natural habitats, as an essential and effective measure to protect endangered species, has become increasingly important for species conservation worldwide, especially for plants facing extinction such as many orchid species (Oldfield, 2009; Godefroid et al., 2011). Plants from ex situ conservation can be linked to in situ conservation via reintroduction. In other words, reintroduction could bridge the gap between conservation theories and practices (Gale et al., 2018). As a consequence, reintroduction programs represent a better choice for orchid protection (Zeng et al., 2012; Wu et al., 2014).

\section{SEED GERMINATION PROMOTING ORCHID MYCORRHIZAL FUNGI (sgOMF) PLAY KEY ROLES IN THE ORCHID REINTRODUCTION}

Orchid conservationists have long been trying to develop ways to reintroduce endangered orchids (Swarts and Dixon, 2009; Johnson, 2011). The current strategies of orchid reintroduction primarily focus on restoration-friendly cultivation, translocation of individual plants, or transplantation of in vitro cultured seedlings (Zeng et al., 2012; Wu et al., 2014). However, these approaches have often been proven to be insufficient and ineffective for in situ protection of some critically endangered orchid species, because of the poor survival rate of the seedlings produced in vitro or the low genetic diversity of the reintroduced plants (Liu et al., 2010; Shao et al., 2017; Hinsley et al., 2018; Sathiyadash et al., 2020).

Due to the lack of endosperm (Yeung, 2017; Zhang et al., 2017; Yeh et al., 2019), the germination of nearly all orchid seeds relies on the specific fungal partner in the wild (Bruns and Read, 2000; Bidartondo and Read, 2008; Merckx et al., 2009; Swarts and Dixon, 2009; Dearnaley et al., 2012; McCormick et al., 2018; Shao et al., 2019). To this end, the seed germinationpromoting fungi, predominantly residing in the protocorm of the germinating seeds are known to play a key role in realizing in situ orchid seed germination and seedling formation (Selosse et al., 2017). Seed germination-promoting fungi generally belong to orchid mycorrhizal fungi (OMF) characterized by the formation of pelotons, inside the cells of orchid roots or germinating seeds (Jacquemyn et al., 2017). Therefore, we focus on sgOMF for orchid reintroduction.

In broad term, OMF could colonize orchid roots (rootoriginated OMF, rOMF) or seeds (seed-originated OMF, sOMF) at distinctive development stages as illustrated in Figure 1A (Peterson et al., 2004; Smith and Read, 2008; Yeh et al., 2019; Favre Godal et al., 2020; Sathiyadash et al., 2020). Theoretically, sgOMF could be potentially identified from sOMF or rOMF (Figure 1). There may be more than one OMF species colonized at a given germinating stage (Bidartondo and Read, 2008; Stöckel et al., 2014; Shao et al., 2017, 2019; Meng et al., 2019a). These sgOMF are saprotrophic and/or endophytic in non-orchid plants (Selosse and Martos, 2014; Wei $\beta$ et al., 
A

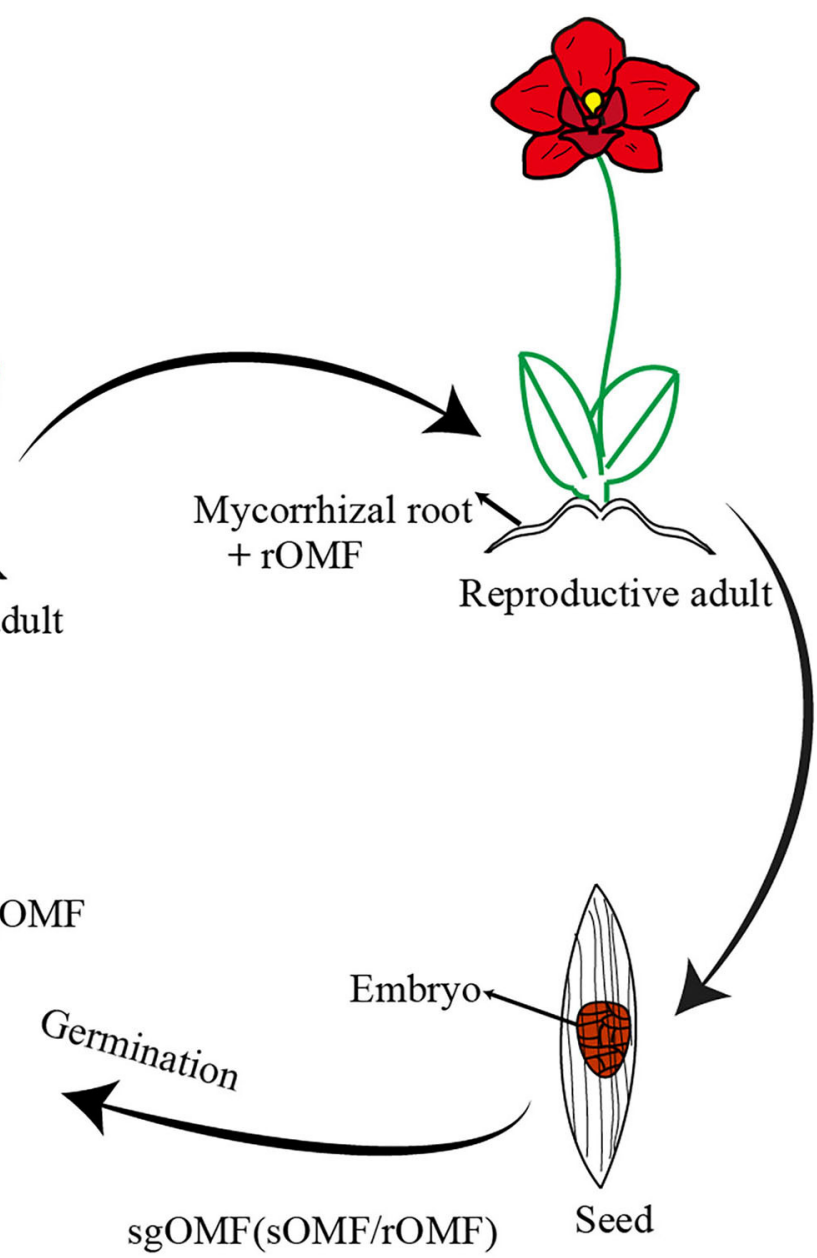

B

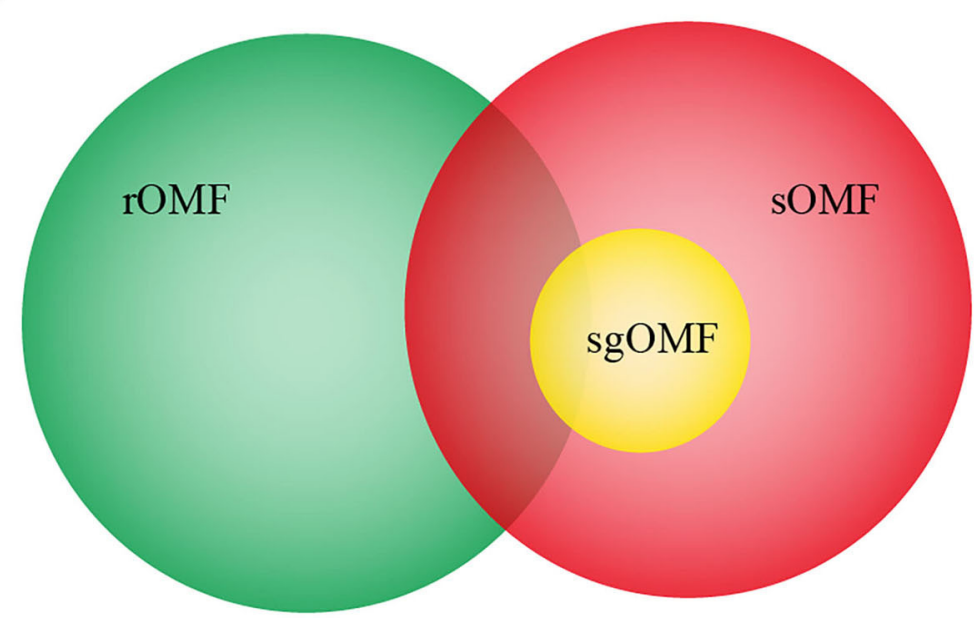

FIGURE 1 | A schematic presentation on the role of rOMF, sOMF, and sgOMF in orchid life cycle and their relationship. (A) A flow chart on orchid life cycle from seed germination to adult plants with positions of rOMF and SOMF in the life cycle indicated. Due to the lack of endosperm, orchid seed germination requires the establishment of symbiosis with seed germination-promoting OMF (sgOMF), mostly found in the protocorm of the germinating seeds (sOMF). Vegetative adults can develop into the reproductive stage and undergo mycorrhization with root-originated OMF (rOMF). (B) A schematic diagram on the relationship among rOMF, sOMF, and sgOMF. Both rOMF and sOMF originate from saprophytic or ectomycorrhizal fungi. Here, sgOMF is the subset of sOMF capable of promoting orchid seed germination in situ. rOMF strains are often different but could be similar to sOMF (see text for more details). 
2016), or concurrently ectomycorrhizal (typical for terrestrial or mycoheterotrophic orchids).

At the genus level, sgOMF generally belong to the polyphyletic "rhizoctonia" aggregate that includes Tulasnellaceae, Ceratobasidiaceae, and Serendipitaceae (Dearnaley et al., 2012; Rasmussen and Rasmussen, 2014; Rasmussen et al., 2015). Some other genera are reported to be involved in symbiotic germination as well, including Mycena (Xu and Guo, 1989), Helicogloea (Kottke et al., 2010), Thanatephorus (Sebastian et al., 2014), and Fusarium (Jiang et al., 2019). Beyond saprobic fungi, some mycoheterotrophic orchid species display symbiosis with Tomentella, Russula, Tuber, or other fungi (Selosse et al., 2004; Julou et al., 2005; Abadie et al., 2006; Bidartondo and Read, 2008; Fochi et al., 2017; Shao et al., 2017).

It was believed that sgOMF generally come from rOMF (e.g., Rasmussen, 1995). Yet, although this may apply to many terrestrial orchids from temperate regions, the general validity of this hypothesis deserves a close examination. At the species level, sgOMF may or may not be identical to those from the corresponding adult roots (McCormick and Jacquemyn, 2014; Meng et al., 2019c). Even for the same fungal species, the isolates from adult roots often fail to promote seed germination in situ, while that fungi from protocorms can (Zelmer and Currah, 1997). The underlying mechanism for this disparity remains to be elucidated (Douhan et al., 2011; Johnson et al., 2012).

The mycorrhizal specificity associated with an orchid in situ seed symbiotic germination is often so restrictive that seeds from many orchids do not germinate or develop without their compatible fungal symbiont (Rasmussen, 1995; Bruns and Read, 2000; Merckx et al., 2009; Tesitelova et al., 2012; Davis et al., 2015; Fay, 2018). Even if seed germination is triggered by close relatives of the target fungus, the orchid seedling may not survive beyond the early developmental stages, which probably explains why some protocorms succeed in germination but fail in further seedling growth. The exact cause of this extreme level of fungal specificity under in situ symbiotic germination is yet to be examined. Nevertheless, coevolution might play a role in this phenomenon: once an appropriate fungus had been recruited. The orchid may have fine-tuned its physiology to adapt to this fungus, thereby making the plants incapable of host-jumping for distantly related fungi (Bidartondo and Bruns, 2002), especially under in situ conditions (Masuhara and Katsuya, 1994; Perkins et al., 1995).

Some sOMF and rOMF can promote orchid seed germination under controlled laboratory conditions, i.e., in vitro, thereby exhibiting potential specificity (Smith and Read, 2008; Rasmussen et al., 2015; Jacquemyn et al., 2017; Shao et al., 2019; Sathiyadash et al., 2020). If those isolates exhibiting potential specificity can successfully stimulate orchid seed symbiotic germination and survival under in situ conditions, they are considered to have ecological specificity. Mycorrhizal roots are historically the major source for identifying fungi that could be used for orchid symbiotic seed germination, since it is much easier to access rOMF than sOMF from protocorms or germinating seeds. The latter are difficult to be detected under natural conditions (Perkins et al., 1995; Zelmer and Currah, 1997; Steinfort et al., 2010; Herrera et al., 2017; Jiang et al., 2019).
Potential specificity may also be possessed by some endophytic or even soil fungi (Jusaitis and Sorensen, 1993; Vujanovic and Vujanovic, 2007; Jiang et al., 2019). However, the effects of rOMF isolates with potential specificity have rarely been evaluated in natural environments or in situ. Among those tested, few of them showing ecological specificity in the wild where the natural factors are uncontrollable and much more complex and variable than those in vitro (Meng et al., 2019c).

While sgOMF may exist among the rOMF (Masuhara and Katsuya, 1994; Bidartondo and Read, 2008; Stöckel et al., 2014), the isolates from adult roots do not always display the ability to promote seed germination. For example, among the Ceratobasidium cornigerum recovered from the field-grown adult roots and the protocorms of Spiranthes lacera at the same site, only the strain from the protocorm, promoted seed germination and seedling development (Zelmer and Currah, 1997). Furthermore, even if the isolate from adult roots promotes in vitro germination and seedling formation, it could fail to work in the field (Batty et al., 2006).

Due to the lack of or lower chance of finding sgOMF from roots, the effective way is to isolate sgOMF from the protocorms or germinating seeds either occurred naturally or induced using in or ex situ baiting. This method allows simultaneous baiting for mycorrhizal fungi that promote orchid seed germination in situ or ex situ from soil or bark (Shao et al., 2017). Symbiotic fungal diversity is sometimes lower in protocorms and seedlings than that in the adult roots (Bidartondo and Read, 2008; Zi et al., 2014). The sOMF usually consist of few fungal strains per germinating seed or seedling and in most cases display a high degree of species-specificity (Masuhara and Katsuya, 1994; Rasmussen and Rasmussen, 2014). However, one should not overlook the possibility that multiple sgOMF species may colonize protocorms or seedlings (Perkins et al., 1995; Bidartondo and Read, 2008; Tesitelova et al., 2012; Stöckel et al., 2014; Meng et al., 2019a; Shao et al., 2019, 2020). Therefore, candidate sgOMF should be firstly evaluated for their potential specificity for seed germination in vitro (Masuhara and Katsuya, 1994; Jacquemyn et al., 2017).

\section{LIMITATIONS OF THE CURRENT ORCHID REINTRODUCTION RELYING ON ROMF}

The concept of using rOMF to promote orchid seed germination was proposed by Bernard in the early 1900's (Selosse et al., 2017) and elaborated later by others including Warcup and Clements in the 1970's and 1980's (Clements et al., 1986). Rasmussen (1995) and Zettler (1997) then suggested the application of rOMF in orchid reintroduction about 20 years ago. There are several preliminary reintroduction reports with rOMF for some green terrestrial orchids including Spiranthes magnicamporum (Anderson, 1991), Spiranthes brevilabris (Stewart et al., 2003), Dactylorhiza hatagirea (Aggarwal and Zettler, 2010), and Dactylorhiza praetermissa (Mckendrick, 1995), two epiphytic orchids Epidendrum nocturnum (Zettler et al., 2007) and Vanda coerulea (Aggarwal et al., 2012) (Table 1). Despite the progress and the role that rOMF play in nutrient uptake from soil 
TABLE 1 | Key orchid reintroduction cases based upon OMF.

\begin{tabular}{|c|c|c|c|c|c|c|}
\hline Taxa & OMF & OMF origin & Specificity & $\begin{array}{l}\text { Materials for } \\
\text { reintroduction }\end{array}$ & Supervision period & References \\
\hline Spiranthes magnicamporum & Epulorhiza repens & Roots & $\begin{array}{l}\text { Potential } \\
\text { specificity }\end{array}$ & Seedling & $\begin{array}{l}\text { Flowering after planted } \\
\text { on calcarious sand } 15 \\
\text { months later }\end{array}$ & Anderson, 1991 \\
\hline Dactylorhizapraetermissa & Unidentified fungus & Roots & $\begin{array}{l}\text { Potential } \\
\text { specificity }\end{array}$ & Seedlings & $\begin{array}{l}\text { Flowering after } 2 \text { or } 3 \\
\text { years }\end{array}$ & Mckendrick, 1995 \\
\hline Spiranthes brevilabris & Epulorhiza repens & Roots & $\begin{array}{l}\text { Potential } \\
\text { specificity }\end{array}$ & Seedlings & $\begin{array}{l}\text { Flowering after planted } \\
6 \text { months later }\end{array}$ & $\begin{array}{l}\text { Stewart et al., } \\
2003\end{array}$ \\
\hline Epidendrumnocturnum & Epulorhiza repens & $\begin{array}{l}\text { Roots of Spiranthes } \\
\text { brevilabris }\end{array}$ & $\begin{array}{l}\text { Potential } \\
\text { specificity }\end{array}$ & Seedlings & Not mentioned & Zettler et al., 2007 \\
\hline Dactylorhiza hatagirea & Ceratobasidium sp. & Roots & $\begin{array}{l}\text { Potential } \\
\text { specificity }\end{array}$ & Seedlings & $\begin{array}{l}\text { Individuals without } \\
\text { flowering after } 2 \text { years } \\
\text { later }\end{array}$ & $\begin{array}{l}\text { Aggarwal and } \\
\text { Zettler, } 2010\end{array}$ \\
\hline Vanda coerulea & Thanatephorus cucumeris & Roots & $\begin{array}{l}\text { Ecological } \\
\text { specificity }\end{array}$ & Seedlings & Individuals after 1 year & $\begin{array}{l}\text { Aggarwal et al., } \\
2012\end{array}$ \\
\hline Dendrobium devonianum & Tulasnella sp. & Protocorms & $\begin{array}{l}\text { Ecological } \\
\text { specificity }\end{array}$ & $\begin{array}{l}\text { Co-sowing seeds } \\
\text { and tulasnella sp. }\end{array}$ & Seedlings after 3 month & Shao et al., 2017 \\
\hline Dendrobium aphyllum & Tulasnella calospora & Protocorms & $\begin{array}{l}\text { Ecological } \\
\text { specificity }\end{array}$ & $\begin{array}{l}\text { Co-sowing seeds } \\
\text { and tulasnella } \\
\text { calospora }\end{array}$ & Seedlings after 3 month & Shao et al., 2018 \\
\hline Dendrobium nobile & Tulasnella sp. & Protocorms & $\begin{array}{l}\text { Ecological } \\
\text { specificity }\end{array}$ & $\begin{array}{l}\text { Co-sowing seeds } \\
\text { and tulasnella sp. }\end{array}$ & Seedlings after 3 month & Shao et al., 2018 \\
\hline
\end{tabular}

(Dearnaley et al., 2012) and vegetative dormancy (McCormick et al., 2018), there are several major limitations of the rOMFbased reintroduction.

Firstly, based on available information, this method hardly led to the re-establishment of a self-sustainable population for critically endangered orchids (Scade et al., 2006). The success of long-term reintroduction can only be achieved if selfsustained populations are established that do not require further human intervention (Scade et al., 2006; Reiter et al., 2016). Orchid mycorrhizal associations are essential for rebuilding selfsustainable wild populations (Scade et al., 2006; Liu et al., 2010; Reiter et al., 2016). Noteworthily, it is the sgOMF from sOMF, but not rOMF, often promote in situ seed germination and the subsequent survival and adaption to the natural habitats (Batty et al., 2006; Shao et al., 2017). In other words, sgOMF can be selected among fungi colonizing protocorms (Shao et al., 2017, 2018), whereas the rOMF in many cases lack the ecological specificity required and fail to help the rebuilding of selfsustained orchid populations.

Some rOMF strains promote seed germination and plantlet formation under laboratory conditions, thereby exhibiting potential specificity (Steinfort et al., 2010; Herrera et al., 2017; Jiang et al., 2019). Some of those individuals even reach the reproductive stage after being transplanted from in vitro environment to the field (Mckendrick, 1995; Stewart et al., 2003). However, and although this was rarely checked, rOMF may not possess suitable inoculum of sgOMF from protocorms and may lack ecological specificity.

Secondly, there is a risk of a failure in identifying any sgOMF from adult orchid roots. For example, all rOMF isolates (Tulasnella spp.) failed to sustain seedling growth in vitro both in the epiphytic Dendrobium exile and terrestrial Arundina graminifolia (Meng et al., 2019b,c). Overall, the limitations and challenges outlined above make rOMF approach impractical for in situ orchid reintroduction (Reiter et al., 2016).

It is clear that although the application of rOMF contributed to reintroduction in the past and may continue to do so in the future, it has several inherent limitations that prompt efforts to develop new approaches. Moreover, the specificities of epiphytic orchids, both in terms of ecology and fungal partners (Martos et al., 2012), call for re-thinking the protocols inherited from the study of North-American and European terrestrial orchids.

\section{TARGETING SgOMF FROM PROTOCORMS AND GERMINATING SEED FOR SUCCESSFUL IN SITU ORCHID REINTRODUCTION}

Under field conditions, sOMF often promote symbiotic seed germination in situ, resulting in the development of plantlets (Masuhara and Katsuya, 1994; Perkins et al., 1995; Smith and Read, 2008; Sathiyadash et al., 2020) (Figure 1), thereby contributing to the rebuilding the orchid populations in the wild. Due to the ecological specificity displayed by sOMF for the symbiotic germination of the target orchid (Perkins et al., 1995; Shao et al., 2017, 2018; Meng et al., 2019c), orchid reintroduction based on sOMF is a natural way compared to that of rOMF. By co-sowing orchid seeds with germination-enhancing sgOMF carrying ecological specificity (see below), the resultant plantlets could serve as not only orchid individuals but also inoculum in the surroundings of the target orchid as a germination 
promoting- mycobiont for continuous orchid germination (Batty et al., 2006; Reiter et al., 2016). It thereby helps to re-establish self-sustainable populations for critically endangered orchids, particularly for those orchids whose ex situ conservation should be conducted in the wild.

Protocorms and seedlings simultaneously associate with multiple OMF in the wild (Shao et al., 2019, 2020). However, cocultures with two or three sgOMF did not increase protocorm formation and seedling establishment. Rather it often resulted in lower germination percentages compared with that of monocultures for D. nobile (Shao et al., 2020). While it seems easy to just perform direct sowing of orchid seeds into their natural habitats for reintroduction, this practice typically leads to sporadic and unstable seedling emergence, owing to the low probability of encountering the target sgOMF in the environment (Jacquemyn et al., 2007; Jersakova and Malinova, 2007; Zi et al., 2014; Shao et al., 2017; Yang et al., 2017).

The concept to use sgOMF carrying ecological specificity for orchid rehabilitation was raised 25 years ago (Perkins et al., 1995). Two decades later, the application of sgOMF from sOMF in orchid restoration finally came into reality for the epiphytic orchid Dendrobium devonianum (Shao et al., 2017). Using packaged seed mixed with symbiotic fungus Tulasnella sp. isolated from protocorms, an efficient reintroduction was conducted, which resulted in the construction of a natural population of this endangered orchid (Shao et al., 2017). With improved methods, the other two threatened orchid species Dendrobium aphyllum and D. nobile have also been successfully reintroduced to the wild, as well as the restoration of another field population of $D$. devonianum (Shao et al., 2018).

Since epiphytes account for $\sim 70 \%$ of all the orchid species (Peterson et al., 2004; Zotz, 2013) and previous reintroduction activities largely focused on terrestrial orchids (Anderson, 1991; Mckendrick, 1995; Stewart et al., 2003; Aggarwal and Zettler, 2010), the co-sowing practice to construct populations for these epiphytic species (Shao et al., 2017, 2018) represents a promising direction and tool in orchid population establishment. Based on the success in the reintroduction of the three epiphytic orchids (Shao et al., 2017, 2018) as discussed above, it is now the time for the application of sgOMF carrying ecological specificity to be tested on other genera. We presume that it will be an effective way to achieve orchid reintroduction in situ.

In contrast to the use of rOMF to produce seedlings ex situ, the reintroduction of the three Dendrobium spp. was based on a novel approach where orchid seeds were directly germinated in situ with the resultant seedlings fully developed into fertile adult plants (Shao et al., 2017, 2018) (Table 1). As nearly all the orchids that naturally germinate are accompanied with sgOMF with ecological specificity, the sOMF-based approach could be broadly applicable for the efficient reintroduction and even natural cultivation of endangered orchidaceae species. One should bear in mind that regardless the rOMF- or sOMF- based studies, there have been no reports on long term analyses over 5 years to check the status of reintroduction if the plantlets emerged from seeds. Thus, monitoring the seedling recruitment over two generations is needed to further verify the result of orchid reintroduction with sOMF (Table 1), especially when reintroducing to sites where the orchids disappeared long time ago. We described the key steps involved in this procedure exploiting sgOMF isolated from protocorms or germinating seeds.

\section{ISOLATION OF SgOMF FROM PROTOCORMS OR GERMINATING SEEDS WITH POTENTIAL SPECIFICITY}

To realize in situ orchid reintroduction, it is essential to identify sgOMF carrying ecological specificity for initiating symbiotic seed germination in situ. As mentioned before, sgOMF isolated from protocorms or seedlings typically promote seed germination not only in vitro but also in the wild, thus showing both potential and ecological specificity (Shao et al., 2017, 2018). The isolates are first verified for potential specificity in laboratories (Zi et al., 2014; Shao et al., 2017, 2019; Meng et al., 2019c) (Figure 2). Yet, sgOMF exhibiting potential specificity does not necessarily carry ecological specificity; as that if they could stimulate in situ seed germination remains unclear. Thus, further screening is required.

\section{APPRAISAL OF ECOLOGICAL SPECIFICITY OF SgOMF FROM PROTOCORMS OR GERMINATING SEED}

After having isolated sgOMF with potential specificity, their in situ co-culture with orchid seeds are conducted to screen for sgOMF capable of promoting seed germination in natural habitats, i.e., carrying ecological specificity (Figure 2). The procedure is supposed to be easily carried out by blending orchid seeds with mycelium and subsequently transferring the mixture to the wild. In reality, however, it faces great challenges due to the high complexity of orchid seed germination in situ (Rasmussen et al., 2015). Hence, innovative and comprehensive measures are needed to design an efficient, reliable, and practical program. Based on our experience in conjunction with considerations of other factors (Shao et al., 2017, 2018), we summarized below the key conditions influencing in situ symbiotic germination.

For epiphytic orchids, maintaining moisture is crucial for achieving in situ seed germination. Previously, orchid seeds were placed on organic substances such as sphagnum moss or bark for germination (Arditti, 1967), which often results in a disappointing outcome largely because of the dry microenvironment surrounding the seeds. To circumvent this problem, paper packets containing a mixture of orchid seeds and fungal hyphae were attached to tree trunks and then wrapped with biodegradable plastic film to retain moisture for producing seedling in situ (Shao et al., 2017). Further supplement of sphagnum moss in paper packets increased the germination rate of D. devonianum to $9.4 \%$ (Shao et al., 2018), as compared to only $0.9 \sim 1.4 \%$ without the inclusion of the moss (Shao et al., 2017). We consider that this 10 -fold increment in the germination rate is primarily owing to the much-improved moisture retention during early germination. Moreover, instead of using nylon net packets in primary reintroduction studies, which could physically block late seedling growth (Shao et al., 


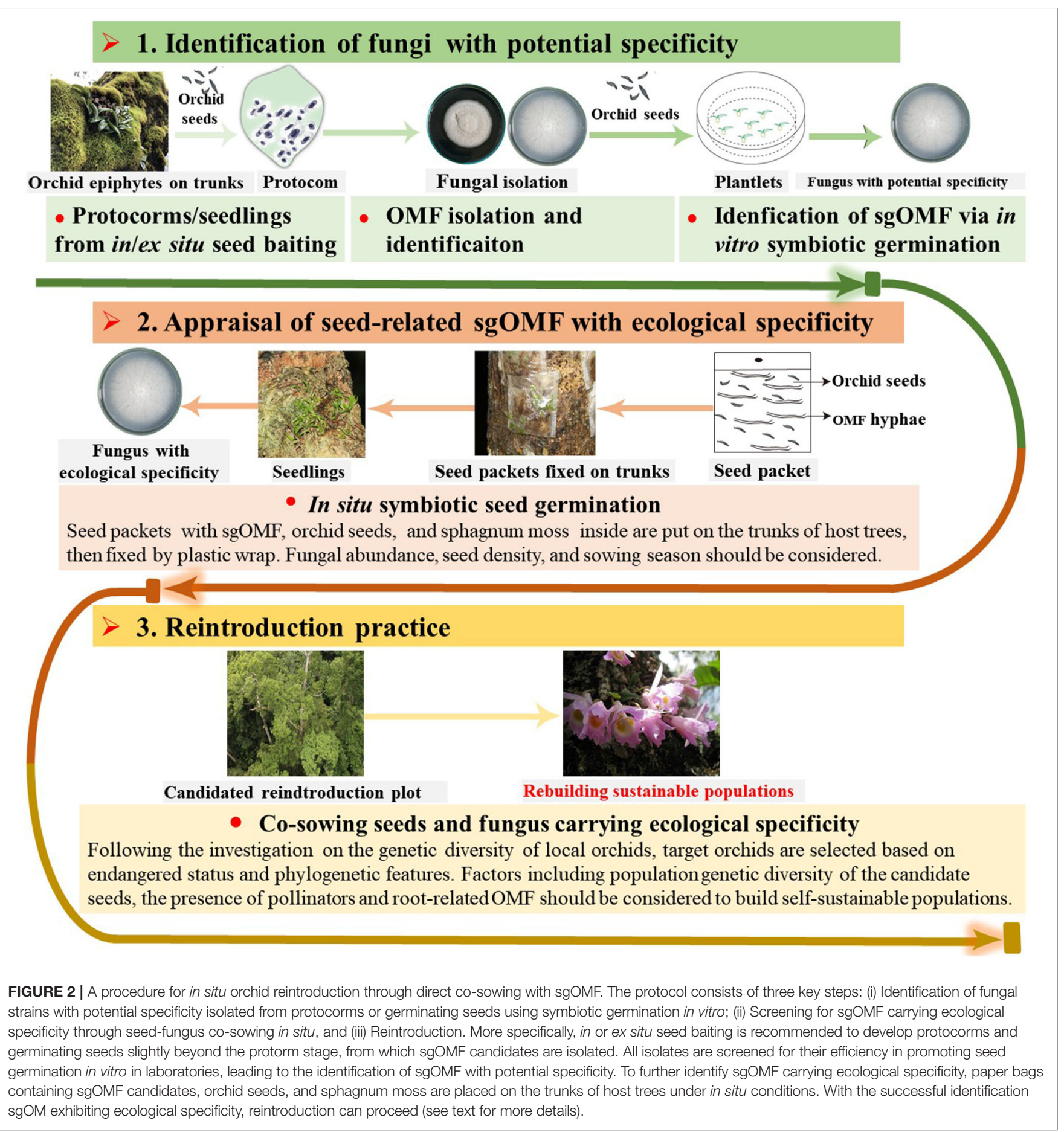

2017, 2018), the paper packets did not constrain seedling emergence. The seedlings can grow readily by enlarging the holes punctured in the wrap, allowing the plantlets to develop naturally without the need for other management intervention (Shao et al., 2018).

Sowing time is another important factor impacting germination in situ as it relates to air temperature and humidity
(Shao et al., 2017, 2018). In situ seed germination and the subsequent formation of protocorm-like bodies and seedlings correlate with the humidity as well as the temperature of the microhabitats across seasons (Shao et al., 2017, 2018; Yang et al., 2017). Therefore, knowledge on the local timing of natural seed dispersal and their germination of the target orchid is required to determine sowing time. 
The density of the fungal patch could also affect orchid seed germination (McCormick et al., 2012, 2018; Favre Godal et al., 2020). The mixture with enough pre-grown fungal hyphae with orchid seeds keeps the dominance of sgOMF, preventing the invasion of competitors (Shao et al., 2017). In practice, fungal mycelium mixed with agar was blended into powder and used at the ratio of $1.0 \mathrm{mg}$ powder to 50 seeds per paper bag based on our successful co-sowing experience. The viability of using the blended fungal powder for seed germination has been verified in our hands both in vitro and in situ. The number of seeds and the amount of powder are controllable and adjustable in each packet that can be easily preserved in the fridge for later reintroduction (Shao et al., 2017, 2018).

The interactions between the host trees for the majority of epiphytic orchids and candidate sgOMF carrying ecological specificity should also be taken into account (Martos et al., 2012; Fay et al., 2015; Rasmussen and Rasmussen, 2018). The sgOMF are susceptible to changes in moisture, $\mathrm{pH}$, and organic amendments in the microhabitat provided by the host trees (McCormick et al., 2012; McCormick and Jacquemyn, 2014; Shao et al., 2018). For example, the percentage of germination of three tested Dendrobium species with sgOMF on the host tree Bauhinia purpurea was higher than that on the Citrus maxima and Camellia assamica (Shao et al., 2018).

We recognize that some orchids potentially utilize a variety of opportunistic mycorrhizal partners to induce seed germination (Waud et al., 2017). Thus, the possibility of requiring more than two strains simultaneously for in situ seed germination cannot be ruled out. In any case, it is necessary to experimentally identify the optimal fungus or fungal combination for seed germination leading to the re-establishment of a self-sustainable population. Following the co-sowing practice, calibrated with the aforementioned key factors, the sgOMF carrying ecological specificity in enhancing in situ germination are identified.

\section{REINTRODUCTION WITH SgOMF CARRYING ECOLOGICAL SPECIFICITY}

With the identification of sgOMF in situ, reintroduction can be conducted in the wild (Figure 2). The rich genetic diversity of the founder population increases the chance of successful plant colonization (Crawford and Whitney, 2010) and the functionality of the ecosystem (Prieto et al., 2015). Thus, for a given target orchid species to be reintroduced, the seeds for co-sowing with sgOMF are ideally chosen from the population with the richest genetic diversity based on assessments such as simple sequence repeats (SSR) (Zotz, 2013). A mix of several populations for one target species of origin may improve the chances of local adaptation at the recipient site. To this end, a minimum of
50-200 individuals is required to establish an effective and self-sustainable population for out-crossing species such as the majority of orchids (Reiter et al., 2016). Further, it is necessary to monitor over a long period of time to determine the sustainability of the rebuilt populations. Given the complex process involved in the re-establishment of orchid (Rasmussen et al., 2015; Shao et al., 2017), other factors including availability of pollinators (Heywood, 2015) and local rOMF (Dearnaley et al., 2012; McCormick et al., 2018) should also be taken into account for successful reintroduction (Figure 2).

\section{CONCLUDING REMARKS AND FUTURE PERSPECTIVES}

We illustrated here the application of sgOMF selected from sOMF in the orchid reintroduction. Through performing in situ co-sowing with sgOMF carrying ecological specificity, coupled with other relevant measures as discussed, it is feasible to achieve an effective and self-sustained population establishment of endangered orchids in the wild. This approach rectifies the shortcomings of the current methods based on rOMF in the genus Dendrobium and should be now tested in more species and regions. The reintroduction of epiphytic orchids is still in its infancy, and many factors in the described protocol can be optimized further or adapted to other species. We call for more applications and updating of our method as we deeply believe that this integrated protocol provides a valuable basis for the reintroduction and protection of threatened orchid species worldwide. This could contribute to the global efforts in orchid reintroduction and realization of in situ restorations of threatened orchid populations in the long run.

\section{AUTHOR CONTRIBUTIONS}

D-KZ, S-CS, and Y-LR conceived the project. LW, YL, D-KZ, S-CS, M-AS, and Y-LR analyzed the selected references. D-KZ, S-CS, M-AS, and Y-LR wrote the manuscript with inputs from all authors. All authors read and approved the final manuscript.

\section{FUNDING}

The work in the authors' laboratories was supported in part by the Australian Research Council (DP180103834), the National Natural Science Foundation of China (31960082, 31600440, and 31400021), and West Light Talent Program of the Chinese Academy of Sciences (Grant No. E1XB011B01). M-AS is currently funded by the Polish National Science Centre (Maestro7-NZ project entitled Orchidomics) and the Fondation de France.

\section{REFERENCES}

Abadie, J. C., Puttsepp, U., Gebauer, G., Faccio, A., Bonfante, P., and Selosse, M. A. (2006). Cephalanthera longifolia (Neottieae, Orchidaceae) is mixotrophic: a comparative study between green and

nonphotosynthetic individuals. Can. J. Bot. 84, 1462-1477. doi: 10.1139/b 06-101

Aggarwal, S., Nirmala, C., Beri, S., Rastogi, S., and Adholeya, A. (2012). In vitro symbiotic seed germination and molecular characterization of associated endophytic fungi in a commercially important and endangered 
Indian orchid Vanda coerulea Griff. ex Lindl. Eur. J. Environ. Sci. 2, 33-42. doi: 10.14712/23361964.2015.36

Aggarwal, S., and Zettler, L. W. (2010). Reintroduction of an endangered terrestrial orchid, Dactylorhiza hatagirea (D. Don). Soo, assisted by symbiotic seed germination-first report from the Indian subcontinent. Nat. Sci. 8, 139-145.

Anderson, A. B. (1991). Symbiotic and asymbiotic germination and growth of Spiranthes magnicamporum (Orchidaceae). Lindreyana 6, 183-186.

Arditti, J. (1967). Factors affecting the germination of orchid seed. Bot. Rev. 33, 1-97. doi: $10.1007 /$ BF02858656

Batty, A. L., Brundrett, M. C., Dixon, K. W., and Sivasithamparam, K. (2006). In situ symbiotic seed germination and propagation of terrestrial orchid seedlings for establishment at field sites. Aust. J. Bot. 54, 375-381. doi: 10.1071/BT04024

Bidartondo, M., and Bruns, T. (2002). Fine-level mycorrhizal specificity in the Monotropoideae (Ericaceae): specificity for fungal species groups. Mol. Ecol. 11, 557-569. doi: 10.1046/j.0962-1083.2001.01443.x

Bidartondo, M. I., and Read, D. J. (2008). Fungal specificity bottlenecks during orchid germination and development. Mol. Ecol. 17, 3707-3716. doi: 10.1111/j.1365-294X.2008.03848.x

Bruns, T. D., and Read, D. J. (2000). In vitro germination of nonphotosynthetic, myco-heterotrophic plants stimulated by fungi isolated from the adult plants. New Phytol. 148, 335-342. doi: 10.1046/j.1469-8137.2000.00766.x

Chase, M. W., Cameron, K. M., Freudenstein, J. V., Pridgeon, A. M., Salazar, G., Van den Berg, C, et al. (2015). An updated classification of Orchidaceae. Bot. J. Linn. Soc. 177, 151-174. doi: 10.1111/boj.12234

Clements, M., Muir, H., and Cribb, P. (1986). A preliminary report on the symbiotic germination of European terrestrial orchids. Kew Bull. 41, 437-445. doi: $10.2307 / 4102957$

Crawford, K., and Whitney, K. (2010). Population genetic diversity influences colonization success. Mol. Ecol. 19, 1253-1263. doi: 10.1111/j.1365-294X.2010.04550.x

Davis, B. J., Phillips, R. D., Wright, M., Linde, C. C., and Dixon, K. W. (2015). Continent-wide distribution in mycorrhizal fungi: implications for the biogeography of specialized orchids. Ann. Bot. 116, 413-421. doi: $10.1093 / \mathrm{aob} / \mathrm{mcv} 084$

Dearnaley, J. D. W., Martos, F., and Selosse, M. A. (2012). "Orchid mycorrhizas: mol ecol, physiology, evolution and conservation aspects," in Fungal Associations. The Mycota, ed B. Hock (Berlin, Heidelberg: Springer), 207-230. doi: 10.1007/978-3-642-30826-0_12

Douhan, G. W., Vincenot, L., Gryta, H., and Selosse, M. A. (2011). Population genetics of ectomycorrhizal fungi: from current knowledge to emerging directions. Fungal Biol. 115, 569-597. doi: 10.1016/j.funbio.2011.03.005

Favre Godal, Q., Gourguillon, L., Riffault Valois, L., Urbain, A., Lordel Madeleine, S., Gindro, K., et al. (2020). Orchids and their mycorrhizal fungi: an insufficiently explored relationship. Mycorrhiza 30, 5-22. doi: $10.1007 /$ s00572-020-00934-2

Fay, M. F. (2018). Orchid conservation: how can we meet the challenges in the twenty-first century? Bot. Stud. 59:16. doi: 10.1186/s40529-018-0232-z

Fay, M. F., Pailler, T., and Dixon, K. W. (2015). Orchid conservation: making the links. Ann. Bot. 116, 377-379. doi: 10.1093/aob/mcv142

Fochi, V., Chitarra, W., Kohler, A., Voyron, S., Singan, V. R., Lindquist, E. A., et al. (2017). Fungal and plant gene expression in the Tulasnella calosporaSerapias vomeracea symbiosis provides clues about nitrogen pathways in orchid mycorrhizas. New Phytol. 213, 365-379. doi: 10.1111/nph.14279

Gale, S. W., Fischer, G. A., Cribb, P. J., and Fay, M. F. (2018). Orchid conservation: bridging the gap between science and practice. Bot. J. Linn. Soc. 186, 425-434. doi: 10.1093/botlinnean/boy003

Givnish, T. J., Spalink, D., Ames, M., Lyon, S. P., Hunter, S. J., Zuluaga, A., et al. (2015). Orchid phylogenomics and multiple drivers of their extraordinary diversification. P. Roy. Soc. B-Biol. Sci. 282, 2108-2111. doi: $10.1098 / \mathrm{rspb} .2015 .1553$

Godefroid, S., Piazza, C., Rossi, G., Buord, S., Stevens, A. D., Aguraiuja, R., et al. (2011). How successful are plant species reintroductions? Biol. Conserv. 144, 672-682. doi: 10.1016/j.biocon.2010.10.003

Govaerts, R., Bernet, P., Kratochvil, K., Gerlach, G., Carr, G., Alrich, P., et al. (2017). World checklist of orchidaceae. Facilitated by the Royal Botanic Gardens, Kew.

Herrera, H., Valadares, R., Contreras, D., Bashan, Y., and Arriagada, C. (2017). Mycorrhizal compatibility and symbiotic seed germination of orchids from the coastal range and Andes in south central Chile. Mycorrhiza 27, 175-188. doi: 10.1007/s00572-016-0733-0

Heywood, V. H. (2015). In situ conservation of plant species-an unattainable goal? Isr. J. Plant Sci. 63, 211-231. doi: 10.1080/07929978.2015.1035605

Hinsley, A., De Boer, H. J., Fay, M. F., Gale, S. W., Gardiner, L. M., Gunasekara, R. S., et al. (2018). A review of the trade in orchids and its implications for conservation. Bot. J. Linn. Soc. 186, 435-455. doi: 10.1093/botlinnean/box083

IUCN (2021). The IUCN red list of threatened species, Version 2021-1. Available online at: www.iucnredlist.org

Jacquemyn, H., Brys, R., Vandepitte, K., Honnay, O., Roldan Ruiz, I., and Wiegand, T. (2007). A spatially explicit analysis of seedling recruitment in the terrestrial orchid Orchis purpurea. New Phytol. 176, 448-459. doi: 10.1111/j.1469-8137.2007.02179.x

Jacquemyn, H., Duffy, K. J., and Selosse, M. A. (2017). "Biogeography of orchid mycorrhizas," in Biogeography of Mycorrhizal Symbiosis, ed L. Tedersoo (Cham: Springer International), 159-177. doi: 10.1007/978-3-319-56363-3_8

Jersakova, J., and Malinova, T. (2007). Spatial aspects of seed dispersal and seedling recruitment in orchids. New Phytol. 176, 237-241. doi: 10.1111/j.1469-8137.2007.02223.x

Jiang, J., Zhang, K., Cheng, S., Nie, Q., Zhou, S. X., Chen, Q., et al. (2019). Fusarium oxysporum KB-3 from Bletilla striata: an orchid mycorrhizal fungus. Mycorrhiza 29, 531-540. doi: 10.1007/s00572-019-00904-3

Johnson, D., Martin, F., Cairney, J. W. G., and Anderson, I. C. (2012). The importance of individuals: intraspecific diversity of mycorrhizal plants and fungi in ecosystems. New Phytol. 194, 614-628. doi: 10.1111/j.1469-8137.2012.04087.x

Johnson, T. R. (2011). Developing a Model of Orchid Seed Germination: In Vitro Studies of the Threatened Florida Species Bletia purpurea. Florida: University of Florida Press.

Julou, T., Burghardt, B., Gebauer, G., Berveiller, D., Damesin, C., and Selosse, M. A. (2005). Mixotrophy in orchids: insights from a comparative study of green individuals and nonphotosynthetic individuals of Cephalanthera damasonium. New Phytol. 166, 639-653. doi: 10.1111/j.1469-8137.2005.01364.x

Jusaitis, M., and Sorensen, B. (1993). Germination of Pterostylis arenicola - an endangered greenhood orchid from south Australia. Sch. Disp. 11, 18-22.

Keppel, G., Gillespie, T. W., Ormerod, P., and Fricker, G. A. (2016). Habitat diversity predicts orchid diversity in the tropical south-west Pacific. J. Biogeogr. 43, 2332-2342. doi: 10.1111/jbi.12805

Kottke, I., Pablo Suarez, J., Herrera, P., Cruz, D., Bauer, R., Haug, I., et al. (2010). Atractiellomycetes belonging to the 'rust' lineage (Pucciniomycotina) form mycorrhizae with terrestrial and epiphytic neotropical orchids. P. Roy. Soc. B-Biol. Sci. 277, 1289-1298. doi: 10.1098/rspb.2009.1884

Liu, H., Luo, Y. B., and Liu, H. X. (2010). Studies of mycorrhizal fungi of Chinese orchids and their role in orchid conservation in China-a review. Bot. Rev. 76, 241-262. doi: 10.1007/s12229-010-9045-9

Liu, Q., Chen, J., Corlett, R. T., Fan, X. L., Yu, D. L., Yang, H. P., et al. (2015). Orchid conservation in the biodiversity hotspot of southwestern China. Conserv. Biol. 29, 1563-1572. doi: 10.1111/cobi.12584

Martos, F., Munoz, F., Pailler, T., Kottke, I., Gonneau, C., and Selosse, M. A. (2012). The role of epiphytism in architecture and evolutionary constraint within mycorrhizal networks of tropical orchids. Mol. Ecol. 21, 5098-5109. doi: 10.1111/j.1365-294X.2012.05692.X

Masuhara, G., and Katsuya, K. (1994). In situ and in vitro specificity between Rhizoctonia spp. and Spiranthes sinensis (Persoon). Ames, var. Amoena (M. bieberstein). hara (Orchidaceae). New Phytol. 127, 711-718. doi: 10.1111/j.1469-8137.1994.tb02974.x

McCormick, M. K., and Jacquemyn, H. (2014). What constrains the distribution of orchid populations? New Phytol. 202, 392-400. doi: 10.1111/nph.12639

McCormick, M. K., Lee Taylor, D., Juhaszova, K., Burnett, R. K., Jr., Whigham, D. F., and O'Neill, J. P. (2012). Limitations on orchid recruitment: not a simple picture. Mol. Ecol. 21, 1511-1523. doi: 10.1111/j.1365-294X.2012.05468.x

McCormick, M. K., Whigham, D. F., and Canchani Viruet, A. (2018). Mycorrhizal fungi affect orchid distribution and population dynamics. New Phytol. 219, 1207-1215. doi: 10.1111/nph.15223

Mckendrick, S. L. (1995). The effects of herbivory and vegetation on laboratory-raised Dactylorhiza praetermissa (Orchidaceae) planted into grassland in southern England. Biol. Conserv. 73, 215-220. doi: 10.1016/0006-3207(94)00111-3 
Meng, Y. Y., Fan, X. L., Zhou, L. R., Shao, S. C., Liu, Q., Selosse, M. A., et al. (2019a). Symbiotic fungi undergo a taxonomic and functional bottleneck during orchid seeds germination: a case study on Dendrobium moniliforme. Symbiosis 79, 1-8. doi: 10.1007/s13199-019-00647-X

Meng, Y. Y., Shao, S. C., Liu, S. J., and Gao, J. Y. (2019b). Do the fungi associated with roots of adult plants support seed germination? A case study on Dendrobium exile (Orchidaceae). Glob. Ecol. Conserv. 17:E00582. doi: 10.1016/j.gecco.2019.e00582

Meng, Y. Y., Zhang, W. L., Selosse, M. A., and Gao, J. Y. (2019c). Are fungi from adult orchid roots the best symbionts at germination? A case study. Mycorrhiza 29, 541-547. doi: 10.1007/s00572-019-00907-0

Merckx, V., Bidartondo, M. I., and Hynson, N. A. (2009). Myco-heterotrophy: when fungi host plants. Ann. Bot. 104, 1255-1261. doi: 10.1093/aob/mcp235

Mounce, R., Smith, P., and Brockington, S. (2017). Ex situ conservation of plant diversity in the world's botanic gardens. Nat. Plants 3, 795-802. doi: 10.1038/s41477-017-0019-3

Oldfield, S. F. (2009). Botanic gardens and the conservation of tree species. Trends Plant Sci. 14, 581-583. doi: 10.1016/j.tplants.2009.08.013

Perkins, A., Masuhara, G., and McGee, P. (1995). Specificity of the associations between Microtis parviflora (Orchidaceae) and its mycorrhizal fungi. Aust. J. Bot. 43, 85-91. doi: 10.1071/BT9950085

Peterson, R. L., Massicotte, H. B., and Melville, L. H. (2004). Mycorrhizas: Anatomy and Cell Biology. Ottawa, Canada: National Research Council Research Press.

Prieto, I., Violle, C., Barre, P., Durand, J. L., Ghesquiere, M., and Litrico, I. (2015). Complementary effects of species and genetic diversity on productivity and stability of sown grasslands. Nat. Plants 1, 1-5. doi: 10.1038/nplants.2015.33

Rasmussen, H. N. (1995). Terrestrial Orchids, From Seed to Mycotrophic Plant. Cambridge: Cambridge University Press. doi: 10.1017/CBO9780511525452

Rasmussen, H. N., Dixon, K. W., Jersáková J., and Těšitelová T. (2015). Germination and seedling establishment in orchids: a complex of requirements. Ann. Bot. 116, 391-402. doi: 10.1093/aob/mcv087

Rasmussen, H. N., and Rasmussen, F. N. (2014). Seedling mycorrhiza: a discussion of origin and evolution in orchidaceae. Bot. J. Linn. Soc. 175, 313-327. doi: 10.1111/boj.12170

Rasmussen, H. N., and Rasmussen, F. N. (2018). The epiphytic habitat on a living host: reflections on the orchid-tree relationship. Bot. J. Linn. Soc. 186, 456-472. doi: 10.1093/botlinnean/box085

Reiter, N., Whitfield, J., Pollard, G., Bedggood, W., Argall, M., Dixon, K., et al. (2016). Orchid re-introductions: an evaluation of success and ecological considerations using key comparative studies from Australia. Plant Ecol. 217, 81-95. doi: 10.1007/s11258-015-0561-x

Ren, H., Jian, S., Liu, H., Zhang, Q. M., and Lu, H. F. (2014). Advances in the reintroduction of rare and endangered wild plant species. Sci. China Life Sci. 57, 603-609. doi: 10.1007/s11427-014-4658-6

Roberts, D. L., and Dixon, K. W. (2008). Orchids. Curr. Biol. 18, R325-R329. doi: 10.1016/j.cub.2008.02.026

Sathiyadash, K., Muthukumar, T., Karthikeyan, V., and Rajendran, K. (2020). "Orchid mycorrhizal fungi: structure, function, and diversity," in Orchid Biology: Recent Trends and Challenges, eds S. Khasim, S. Hegde, M. González-Arnao, and K. Thammasiri (Singapore: Springer), 239-280. doi: 10.1007/978-981-32-9456-1_13

Scade, A., Brundrett, M. C., Batty, A. L., Dixon, K. W., and Sivasithamparam, K. (2006). Survival of transplanted terrestrial orchid seedlings in urban bushland habitats with high or low weed cover. Aust. J. Bot. 54, 383-389. doi: 10.1071/BT04025

Sebastian, F., Vanesa, S., Eduardo, F., Graciela, T., and Silvana, S. (2014). Symbiotic seed germination and protocorm development of Aa achalensis Schltr., a terrestrial orchid endemic from Argentina. Mycorrhiza 24, 35-43. doi: 10.1007/s00572-013-0510-2

Selosse, M. A. (2014). The latest news from biological interactions in orchids: in love, head to toe. New Phytol. 202, 337-340. doi: 10.1111/nph.12769

Selosse, M. A., Faccio, A., Scappaticci, G., and Bonfante, P. (2004). Chlorophyllous and achlorophyllous specimens of Epipactis microphylla (Neottieae, Orchidaceae) are associated with ectomycorrhizal Septomycetes, including truffles. Microb. Ecol. 47, 416-426. doi: 10.1007/s00248-003-2034-3

Selosse, M. A., and Martos, F. (2014). Do chlorophyllous orchids heterotrophically use mycorrhizal fungal carbon? Trends Plant Sci. 19, 683-685. doi: 10.1016/j.tplants.2014.09.005
Selosse, M. A., Minasiewicz, J., and Boullard, B. (2017). An annotated translation of Noel Bernard's 1899 article 'on the germination of Neottia nidus-avis. Mycorrhiza 27, 611-618. doi: 10.1007/s00572-017-0774-z

Shao, S. C., Burgess, K. S., Cruse Sanders, J. M., Liu, Q., Fan, X. L., and Gao, J. (2017). Using in situ symbiotic seed germination to restore overcollected medicinal orchids in southwest China. Front. Plant Sci. 8:888. doi: $10.3389 /$ fpls. 2017.00888

Shao, S. C., Mohandass, D., and Gao, J. Y. (2018). In situ symbiotic seed germination in Dendrobium spp. (Orchidaceae): implications for orchid restoration. Cah. Soc. Fr. Orch. 9, 36-46.

Shao, S. C., Wang, Q. X., Beng, K., Zhao, D. K., and Jacquemyn, H. (2020). Fungi isolated from host protocorms accelerate symbiotic seed germination in an endangered orchid species (Dendrobium chrysotoxum) from southern China. Mycorrhiza 30, 529-539. doi: 10.1007/s00572-020-00964-w

Shao, S. C., Xi, H. P., and Mohandass, D. (2019). Symbiotic mycorrhizal fungi isolated via ex situ seed baiting induce seed germination of Dendrobium catenatum Lindl. (Orchidaceae). Appl. Ecol. Environ. Res. 17, 9753-9771. doi: 10.15666/aeer/1704 97539771

Smith, S. E., and Read, D. J. (2008). Mycorrhizal Symbiosis. London: Academic Press.

Steinfort, U., Verdugo, G., Besoain, X., and Cisternas, M. A. (2010). Mycorrhizal association and symbiotic germination of the terrestrial orchid Bipinnula fimbriata (Poepp.) Johnst (Orchidaceae). Flora 205, 811-817. doi: 10.1016/j.flora.2010.01.005

Stewart, S. L., Zettler, L. W., Minso, J., and Brown, P. M. (2003). Symbiotic germination and reintroduction of Spiranthes brevilabris Lindley, an endangered orchid native to Florida. Selbyana 24, 64-70. doi: 10.2307/41750957

Stöckel, M., Těšitelová, T., Jersáková, J., Bidartondo, M. I., and Gebauer, G. (2014). Carbon and nitrogen gain during the growth of orchid seedlings in nature. New Phytol. 202, 606-615. doi: 10.1111/nph.12688

Swarts, N. D., and Dixon, K. W. (2009). Terrestrial orchid conservation in the age of extinction. Ann. Bot. 104, 543-556. doi: 10.1093/aob/mcp025

Tesitelova, T., Tesitel, J., Jersakova, J., Rihova, G., and Selosse, M. A. (2012). Symbiotic germination capability of four Epipactis species (Orchidaceae) is broader than expected from adult ecology. Am. J. Bot. 99, 1020-1032. doi: 10.3732/ajb.1100503

Vujanovic, V., and Vujanovic, J. (2007). Mycovitality and mycoheterotrophy: where lies dormancy in terrestrial orchid and plants with minute seeds? Symbiosis 44, 93-99.

Wang, Q. X., Shao, S. C., Su,Y., Hu X, Shen, Y., and Zhao, D. K. (2019). A novel case of autogamy and cleistogamy in Dendrobium wangliangii: a rare orchid distributed in the dry-hot valley. Ecol. Evol. 9, 12906-12914. doi: 10.1002/ece3.5772

Waud, M., Brys, R., Van Landuyt, W., Lievens, B., and Jacquemyn, H. (2017). Mycorrhizal specificity does not limit the distribution of an endangered orchid species. Mol. Ecol. 26, 1687-1701. doi: 10.1111/mec.14014

Wei $\beta$, M., Waller, F., Zuccaro, A., and Selosse, M. A. (2016). Sebacinales - one thousand and one interactions with land plants. New Phytol. 211, 20-40. doi: $10.1111 / \mathrm{nph} .13977$

Willis, K. J. (2017). State of the world's plants report-2017. Royal Botanic Gardens, Kew.

Wu, K. L., Zeng, S. J., Lin, D. N., Teixeira da Silva, J. A., Bu, Z. Y., Zhang, J. X., et al. (2014). In vitro propagation and reintroduction of the endangered Renanthera imschootiana Rolfe. PLoS ONE 9:e110033. doi: 10.1371/journal.pone.0110033

$\mathrm{Xu}$, J. T., and Guo, S. X. (1989). Fungus associated with nutrition of seed germination of Gastrodia elata-Mycena osmundicola Lange. Acta Mycol. Sinica $8,221-226$

Yang, F. S., Sun, A. H., Zhu, J., Downing, J., Song, X. Q., and Liu, H. (2017). Impacts of host trees and sowing conditions on germination success and a simple ex situ approach to generate symbiotic seedlings of a rare epiphytic orchid endemic to Hainan island, China. Bot. Rev. 83, 74-86. doi: 10.1007/s12229-017-9178-1

Yeh, C. M., Chung, K., Liang, C. K., and Tsai, W. C. (2019). New insights into the symbiotic relationship between orchids and fungi. Appl Sci 9:585. doi: 10.3390/app9030585

Yeung, E. C. (2017). A perspective on orchid seed and protocorm development. Bot. Stud. 58:33. doi: 10.1186/s40529-017-0188-4

Zelmer, C., and Currah, R. (1997). Symbiotic germination of Spiranthes lacera (Orchidaceae). with a naturally occurring endophyte. Lindleyana 12, 142-148. 
Zeng, S. J., Wu, K., da Silva, J. A. T., Zhang, J., Chen, Z., Xia, N., et al. (2012). Asymbiotic seed germination, seedling development and reintroduction of Paphiopedilum wardii Sumerh., an endangered terrestrial orchid. Sci. Hortic. 138, 198-209. doi: 10.1016/j.scienta.2012.02.026

Zettler, L. W. (1997). Terrestrial orchid conservation by symbiotic seed germination: techniques and perspectives. Selbyana 18, 188-194.

Zettler, L. W., Poulter, S. B., McDonald, K. I., and Stewart, S. L. (2007). Conservation-driven propagation of an epiphytic orchid (Epidendrum nocturnum) with a mycorrhizal fungus. HortScience 42, 135-139. doi: 10.21273/HORTSCI.42.1.135

Zhang, G. Q., Liu, K. W., Li, Z., Lohaus, R., Hsiao, Y. Y., Niu, S. C., et al. (2017). The Apostasia genome and the evolution of orchids. Nature 549, 379-383. doi: 10.1038 /nature23897

Zi, X. M., Sheng, C. L., Goodale, U. M., Shao, S. C., and Gao, J. Y. (2014). In situ seed baiting to isolate germination-enhancing fungi for an epiphytic orchid, Dendrobium aphyllum (Orchidaceae). Mycorrhiza 24, 487-499. doi: 10.1007/s00572-014-0565-8
Zotz, G. (2013). The systematic distribution of vascular epiphytes-a critical update. Bot. J. Linn. Soc. 171, 453-481. doi: 10.1111/boj.12010

Disclaimer: The authors alone are responsible for the content and functionality of these materials.

Conflict of Interest: The authors declare that the research was conducted in the absence of any commercial or financial relationships that could be construed as a potential conflict of interest.

Copyright $\odot 2021$ Zhao, Selosse, Wu, Luo, Shao and Ruan. This is an open-access article distributed under the terms of the Creative Commons Attribution License (CC $B Y)$. The use, distribution or reproduction in other forums is permitted, provided the original author(s) and the copyright owner(s) are credited and that the original publication in this journal is cited, in accordance with accepted academic practice. No use, distribution or reproduction is permitted which does not comply with these terms. 